\title{
Influência do Tipo de Chanfro, Tecimento e Sentido de Laminação na Distorção Angular em Soldagem GMAW-P Robotizada de Alumínio
}

\author{
(Influence of the Type of Groove, Weaving and Rolling Direction on the Angular Distortion in Robotic GMAW-P Aluminum \\ Welding)
}

\author{
Rafael Coraini ${ }^{1}$, Yukio Kobayashi ${ }^{1}$, Gilberto de Magalhães Bento Gonçalves ${ }^{l}$ \\ ${ }^{1}$ UNESP - Universidade Estadual Paulista "Julio de Mesquita Filho”, Departamento de Engenharia Mecânica, Campus de Bauru, \\ SP, Brasil,rafaelcoraini@jacto.com.br,kio@feb.unesp.br, gilberto@feb.unesp.br
}

\begin{abstract}
Resumo
O interesse da indústria em ter um maior controle das deformações provocadas pela soldagem se deve ao fato das tolerâncias dimensionais e geométricas estarem cada vez mais precisas nas especificações de projeto, motivando a engenharia de fabricação a desenvolver processos estáveis e que garantam a rotina de produção. Visando isso, o presente trabalho tem como objetivo analisar o quanto situações rotineiras utilizadas na soldagem automatizada de alumínio podem influenciar nas deformações angulares deste material. Utilizando a liga AA $5052 \mathrm{H34}$, e a soldagem automatizada no processo GMAW pulsado, foram aplicados três tipos de tecimento ao longo do comprimento da solda, em juntas de topo montadas sem chanfro e com chanfro de $60^{\circ}$, dispostas tanto transversais quanto longitudinais ao sentido de conformação da chapa. A medição das deformações foi realizada por um braço tridimensional, antes e após a soldagem, em três regiões distintas nas placas de teste. O perfil do cordão de solda foi o fator determinante para as diferentes formas das deformações encontradas, assim como revelado pelas análises macrográficas. A junta com chanfro de $60^{\circ}$ apresentou maiores amplitudes das deformações que a junta sem chanfro. A oscilação da tocha não foi uma variável de influência estatisticamente significativa nessas amplitudes.
\end{abstract}

Palavras-chave: soldagem automatizada; deformações angulares; sentido de conformação; oscilação da tocha.

Abstract: The industry's interest in having a greater control of the deformations caused by welding is due to the geometric and dimensional tolerances been more and more precise in the project specifications, motivating the manufacturing engineering to develop stable processes and to ensure routine production. Aiming at it, the main goal of this present work is to analyze how much routine situations used in automatic aluminum welding can influence on the angular deformations of this material. Using the alloy AA 5052 H34, and the automatic welding in pulsed GMAW process, three types of weaving were applied throughout the length of the weld, in butt joints assembled without groove and with $60^{\circ}$ single-V-groove, arranged transversely as well as longitudinally to the rolling direction of the plate. The measurement of the deformations was made by a three-dimensional equipment, before and after the welding, in three distinct regions in the specimens. The profile of the weld bead was the main factor for the different types of deformations found, as revealed by macrographical analysis. The $60^{\circ}$ single-V-groove had higher amplitudes of deformations as the joint without groove. The torch oscillation wasn't a variable of statistically significant influence on this amplitudes.

Key-words: automatic welding; angular deformations; rolling direction; torch oscillation.

\section{Introdução}

A globalização e o avanço tecnológico crescente têm induzido a engenharia de fabricação a buscar reduções nos custos, aumentos na produtividade e na qualidade do produto. A automação dos processos e o emprego de materiais que possuam elevada resistência mecânica e baixo peso específico são alguns dos requisitos importantes a serem considerados

(Recebido em 09/09/2010; Texto final em 30/06/2011).

Artigo originalmente publicado no CONSOLDA 2009 nesse cenário. No que concerne aos materiais, cada vez mais as ligas de alumínio têm sido escolhidas, sobretudo em substituição aos aços, pois apresentam excelente resistência a corrosão, assim como elevada relação resistência/peso. Toros, Ozturk e Kacar [1] mostram que a demanda por alumínio na indústria automotiva européia e norte-americana praticamente dobrou nos últimos vinte anos.

Até meados da década de 70, a soldagem do alumínio e suas ligas era, no Brasil, uma prática metalúrgica de poucos iniciados, e sua maior aplicação ocorreu desse período em diante [2]. Um dos processos mais utilizados na área industrial para a soldagem desse material é o MIG pulsado (GMAW-P). Devido às altas velocidades de deslocamento possíveis, os sistemas robotizados são amplamente empregados nesse processo e se mostram como 
uma alternativa eficaz para revigorar a competência produtiva e de qualidade, tornando essa uma das tecnologias de maior interesse na indústria seriada de equipamentos pesados [3,4]. Vieira e Bracarense [5], ao soldar juntas formadas por tubos de alumínio, utilizando o processo GMAW robotizado, concluíram que essa tecnologia é perfeitamente viável de ser aplicada, podendo ser utilizada em muitas posições, ampliando assim sua utilização na indústria, já que possui grande versatilidade.

O tecimento (trançamento ou oscilação da tocha) é uma técnica de soldagem utilizada, principalmente, para se depositar um cordão mais largo, garantir a fusão das paredes laterais da junta, estabilizar a poça fora da posição plana e expulsar gases. Diversos modos de tecimento são utilizados na prática, os quais podem ser realizados dependendo do tipo de solda, da preparação da junta e da habilidade do soldador. Estudos mostraram que a amplitude do tecimento deve ser relacionada com o diâmetro do arame, e valores ótimos foram encontrados quando essa amplitude ficou entre 2,0 e 2,5 vezes o diâmetro [6]. A frequência, assim como a amplitude e os tempos de parada central e lateral, constitui um dos principais parâmetros de regulagem, podendo ser estimada através de equações, e da relação com a amplitude, em que pequenas amplitudes necessitam de frequências altas de oscilação para manter as propriedades ideais do cordão, e viceversa [7].

A liga de alumínio magnésio AA 5052, assim como as demais da série 5000, não apresenta mudanças de fase no estado sólido durante a soldagem [8]. Para esse tipo de liga, no estado recozido $(\mathrm{O})$, a mudança estrutural mais marcante é o crescimento do grão. Já no estado encruado (H3X), a ZTA apresenta, além de uma região de crescimento de grão adjacente à $\mathrm{ZF}$, uma região recristalizada localizada um pouco mais afastada [9]. Segundo Fraga [10], a direção de soldagem em relação ao sentido de laminação da chapa é uma variável de influência estatisticamente significativa sobre a quantidade de distorções em ligas de alumínio magnésio. A realização da solda sobre chapa na direção paralela ao sentido de laminação da chapa provoca maior distorção do material, quando comparada à soldagem com o cordão perpendicular ao sentido de laminação, sendo que a textura de deformação encontrada no metal base (tipo Brass) foi a principal variável microestrutural para tal conclusão.

Durante o processo de soldagem a distribuição de temperaturas não é uniforme, ultrapassando em algumas regiões a chamada "temperatura de escoamento do material". Essa é a temperatura na qual a tensão de escoamento do material é praticamente zero e ele não resiste às tensões de origem térmica desenvolvidas no seu interior. A literatura cita, para as ligas de alumínio mais resistentes, temperaturas entre 260 e $300{ }^{\circ} \mathrm{C}$ [11]. Nesta temperatura se inicia o processo de deformação plástica localizada no material e que permanece após o resfriamento. Em soldagem, essas deformações são chamadas de distorções. Em geral, a afirmação de que a deformação é resultado das tensões residuais não é correta. Radaj [12] explica que as deformações e as tensões residuais são antagônicas, ou seja, tensões altas ocorrem quando as deformações são restringidas, e tensões baixas surgem quando as deformações não são restringidas.

Os três principais tipos de distorções transientes que ocorrem durante a soldagem de juntas de topo são: contração transversal, que ocorre perpendicular ao cordão de solda, contração longitudinal, que ocorre paralela ao cordão de solda, e distorção angular, que consiste em uma rotação em torno do cordão de solda, podendo ser encontrada também em sentido longitudinal (flexão longitudinal), sendo gerada principalmente pela largura e profundidade da zona de fusão relativa à espessura da chapa [11,13]. Porém, o cálculo preciso da extensão da seção transversal de metal fundido durante a soldagem é bastante difícil e as fórmulas empíricas para sua determinação são aplicáveis somente em condições específicas. Sabe-se, entretanto, que essa área é proporcional a área do chanfro (tipo de junta) e à quantidade de metal depositado. A área transversal de metal fundido é definida em duas regiões: acima e abaixo da linha média das chapas na direção vertical (espessura), levando em conta esses dois fatores (chanfro e metal depositado) [11]. A distorção angular e flexão longitudinal ocorrem geralmente em juntas de topo quando a contração transversal e longitudinal não são uniformes acima e abaixo da linha média das chapas na direção vertical [13].

Tendo em vista o descrito nos parágrafos anteriores e utilizando a liga AA 5052 H34, o objetivo principal deste trabalho foi estudar o comportamento das distorções angulares em juntas de topo, soldadas pelo processo GMAW pulsado robotizado, sob condições diferenciadas de tecimentos, tipos de chanfros e sentido de laminação da chapa em relação ao cordão de solda. Visando adequar os processos de alguns produtos soldados em alumínio de maneira semi-automática, a análise de viabilidade técnica da soldagem robotizada desse tipo de liga se fez necessária dentro do ambiente industrial na empresa onde os testes foram realizados.

\section{Materiais e Métodos}

Para a realização deste trabalho foi utilizada uma célula de soldagem robotizada, a qual é composta, basicamente, de manipulador (robô), fonte de soldagem, controlador, cabeçote alimentador de arame, tocha de soldagem refrigerada, unidade de refrigeração da tocha e unidade de limpeza do bocal.

A fonte de soldagem é multiprocessos, alimentação de corrente contínua (CC) e inversão primária. Possui 24 programas pré-estabelecidos de fábrica para uso com o processo GMAW pulsado. Utilizou-se o programa no modo padrão 7 (STD), como pode ser visto na Tabela 1, sendo que apenas esses parâmetros de pulso são disponibilizados no manual do equipamento.

Tabela 1 - Parâmetros utilizados na fonte de soldagem no modo padrão 7 .

\begin{tabular}{c|c|c|c|c|c|c}
$\begin{array}{c}\text { Programaçáo } \\
\text { STD }\end{array}$ & $\begin{array}{c}\text { Tipo de } \\
\text { arame }\end{array}$ & $\begin{array}{c}\text { Diàmetro do } \\
\text { arame (mm) }\end{array}$ & $T_{p}(\mathrm{~ms})$ & $\mathrm{L}_{p}(\mathrm{~A})$ & $\mathrm{V}_{\mathrm{b}}$ (V) & $\begin{array}{c}\text { Mistura de } \\
\text { gas }\end{array}$ \\
\hline 7 & Aluminio & 1.2 & 1,4 & 275 & 17 & $100 \% \mathrm{Ar}$ \\
\hline
\end{tabular}

O manipulador possui 6 eixos, denominados eixos S, L, U, $\mathrm{R}, \mathrm{B}$ e T, utilizado especificamente para processos de soldagem, sendo que sua configuração é do tipo articulada. O cabeçote de alimentação pode tracionar o arame de duas maneiras: em 

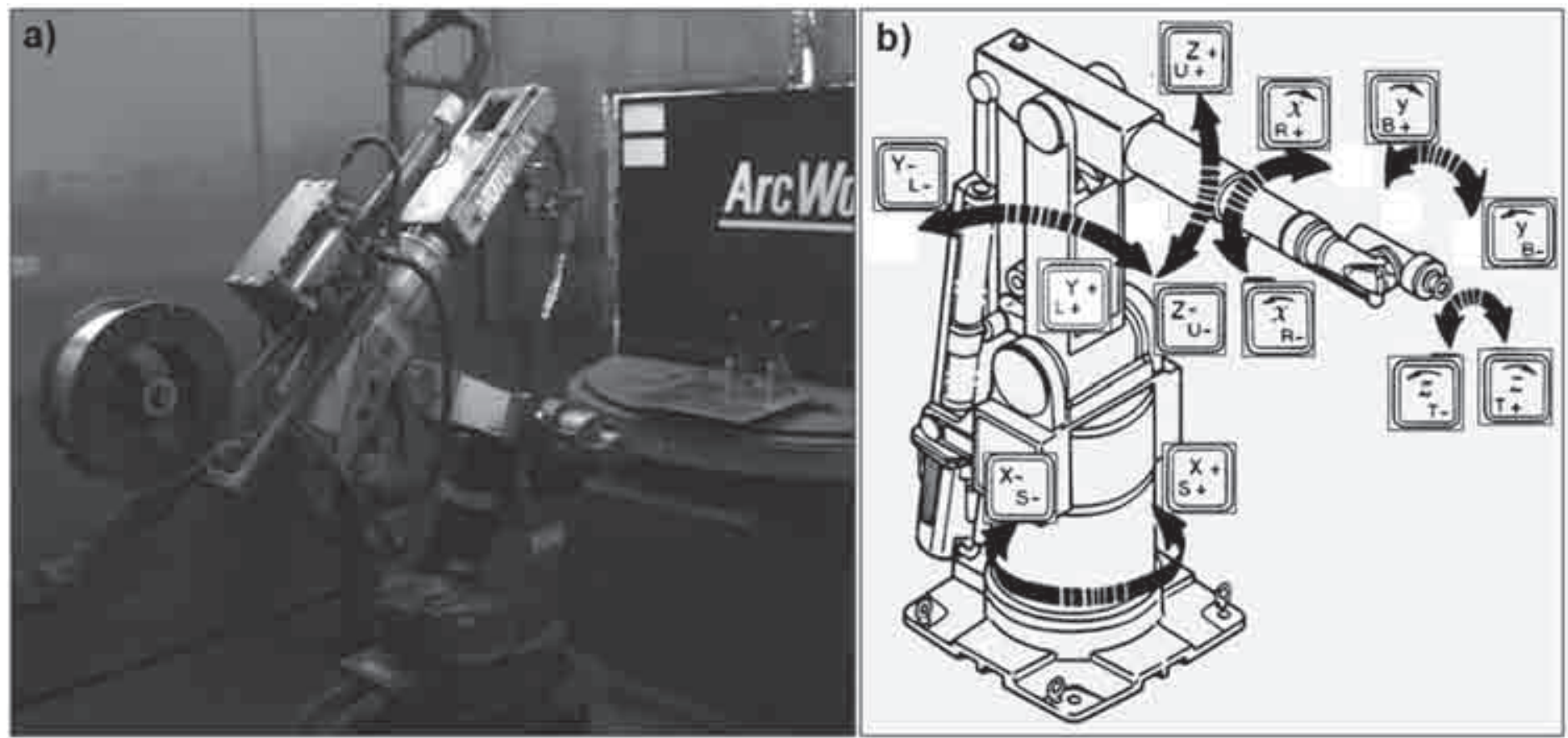

Figura 1 - Robô de soldagem utilizado: (a) disposição dos equipamentos para a soldagem; e (b) ilustração dos eixos (Motoman).

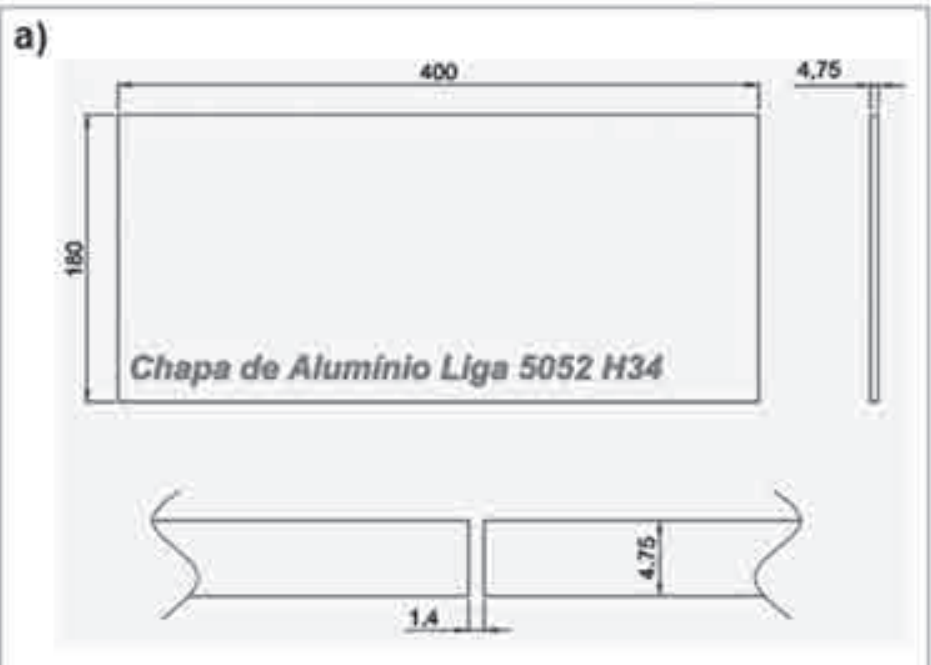

b)
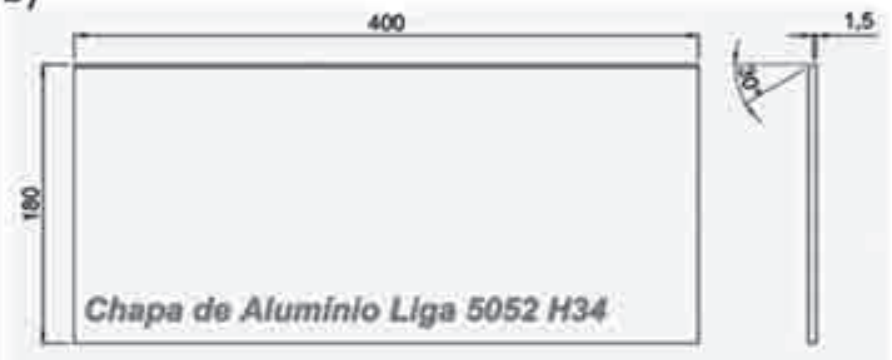

Figura 2 - Dimensões das juntas: (a) junta 1 (sem chanfro); e (b) junta 2 (chanfro $60^{\circ}$ ).

barricas ou carretéis. A Figura 1 mostra o descrito. Utilizouse carretel de $7 \mathrm{~kg}$, com especificação AWS ER5356, segundo AWS D1.2 [14], e diâmetro de arame de 1,2 mm. O cabeçote em questão está configurado com quatro roldanas com canais em "U" ideais para trabalho com arame de alumínio.

A tocha de soldagem é refrigerada a água e com conduite de teflon, difusor de gás, bicos de contato $\mathrm{CuCrZr}$, além do bocal cônico de diâmetro 15,5 mm. Como gás de proteção, utilizou-se argônio puro em cilindro, numa vazão de 13 1/min em todos os ensaios. $\mathrm{O}$ gabarito de soldagem foi elaborado de modo a deixar apenas duas pequenas áreas de contato com a placa de teste (PT) e apenas dois elementos de fixação próximos a borda de umas das chapas da PT, influenciando o menos possível na distorção.

As placas de teste (PTs) foram constituídas da liga AA 5052
H34, compostas de 02 chapas de $400 \times 180 \times 4,75 \mathrm{~mm}$. As dimensões da PT foram baseadas na Norma AWS D1.2 [14] no que diz respeito a qualificação do procedimento de soldagem para a aplicação prática correspondente ao processo que está sendo estudado. Já as dimensões dos dois tipos de juntas foram baseadas na literatura e estão esquematizadas na Figura 2. O corte foi realizado por guilhotina hidráulica.

A medição da distorção angular foi realizada por uma máquina de medição tridimensional portátil de braço articulado, com alcance de medição de $3000 \mathrm{~mm}$. Para os ensaios de tração, foi utilizada uma máquina com célula de carga de $15.000 \mathrm{kgf}$ e velocidade de ensaio de $5 \mathrm{~mm} / \mathrm{min}$.

Foram soldadas 24 PTs e 14 PTRs, de acordo com as condições mostradas na Tabela 2. A abreviação adotada PTT 
refere-se às placas de teste montadas a partir das chapas cortadas no sentido transversal de laminação, enquanto PTL refere-se às placas de teste montadas a partir das chapas cortadas no sentido longitudinal. As PTs identificadas como PTTR e PTLR se referem, respectivamente, às placas de testes reservas montadas a partir das chapas cortadas no sentido transversal e longitudinal de laminação, caso fosse necessária a substituição de alguma PT por um possível imprevisto nos testes. Todas as placas de teste foram soldadas com passe único.

Tabela 2 - Denominação adotada para as PTs.

\begin{tabular}{|c|c|c|c|}
\hline \multicolumn{3}{|c|}{ Abreviaçäo adotada } & $\begin{array}{c}\text { Substituiçāo } \\
\text { possivel }\end{array}$ \\
\hline \multirow{12}{*}{$\begin{array}{c}\text { Junta } 1 \text { (sem } \\
\text { chanfro) }\end{array}$} & \multirow{4}{*}{ (1) Sem tecimento } & PTT1 & \\
\hline & & PT12 & PTTR2 \\
\hline & & PTL1 & PTLR2 \\
\hline & & PTL2 & \\
\hline & \multirow{4}{*}{$\begin{array}{l}\text { (2) Tecimento } \\
\text { "Triangular" }\end{array}$} & PTT3 & PTIR3 \\
\hline & & PTT4 & \\
\hline & & PTL3 & PTLR4 \\
\hline & & PTL4 & \\
\hline & \multirow{4}{*}{$\begin{array}{l}\text { (3) Tecimento } \\
\text { "Vai-Vem" } \\
\rightarrow \rightarrow-\rightarrow\end{array}$} & PTT5 & \\
\hline & & PTT6 & PITRI \\
\hline & & PTL5 & PTLR3 \\
\hline & & PTL6 & PTLR1 \\
\hline \multirow{12}{*}{$\begin{array}{c}\text { Junta } 2 \\
\text { (chanfro } 60^{\circ} \text { ) }\end{array}$} & \multirow[t]{4}{*}{ (1) Sem tecimento } & PाTा & \\
\hline & & PTT8 & \\
\hline & & PTL7 & PTLR5 \\
\hline & & PTL8 & \\
\hline & \multirow{4}{*}{$\begin{array}{l}\text { (2) Tecimento } \\
\text { "Triangular" }\end{array}$} & PTT9 & PIRA/PITRE \\
\hline & & PTा10 & PITR5 \\
\hline & & PTL9 & PTLR7 \\
\hline & & PTL10 & \\
\hline & \multirow{4}{*}{$\begin{array}{c}\text { (3) Tecimento } \\
\text { "Vai-Vem" } \\
\stackrel{\longrightarrow}{\longrightarrow} \rightarrow \longrightarrow\end{array}$} & PाT11 & \\
\hline & & Pा112 & \\
\hline & & PTL11 & PTLR6/PTLR8 \\
\hline & & PTL12 & \\
\hline
\end{tabular}

Para cada tipo de junta, foram escolhidos três tipos de tecimentos, normalmente utilizados no chão de fábrica, sendo: (1) sem tecimento; (2) tecimento "Triangular"; e (3) tecimento "Vai-Vem". Para cada tipo de tecimento foram montadas quatro tipos de PTs, duas com chapas retiradas no sentido transversal de laminação, e duas com chapas retiradas no sentido longitudinal.

O sentido de laminação das chapas foi informado pelo fornecedor do material base. Analisando-se os resultados de Espectrometria, no aparelho Espectrômetro BAIRD FSQ, pode-se constatar que o material usado neste trabalho encontrase dentro das especificações estabelecidas na norma ASTM B209M-04 [15].

Foi realizada uma calibração prévia nos parâmetros de soldagem antes dos testes, para se obter a correta relação entre o argumento programado no Teach-Pendant e a corrente de soldagem média na saída da fonte, de acordo com a recomendação do manual do controlador do robô. A reta obtida pode ser vista na Figura 3. Através do software Excel 2007, utilizando-se a ferramenta de Análise de Dados Regressão, foi analisada a tendência de comportamento das duas variáveis. Obteve-se um coeficiente de correlação linear de Pearson (r) de 0,98444 , ou seja, forte correlação linear positiva entre as variáveis. Somado a isso, como os valores-P foram de 0,00715 e 0,00006 , ambos menores que 0,05 , conclui-se que esse modelo é significativo estatisticamente em representar a correlação linear entre as variáveis.

\section{Argumento $X$ Corrente}

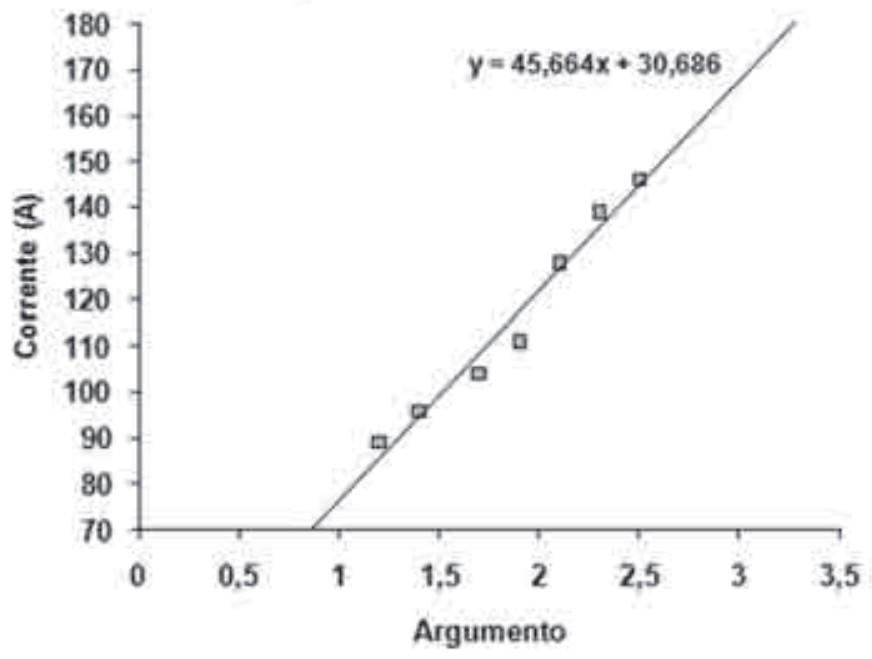

Figura 3 - Reta gerada na calibração, relacionando os valores de argumento programados no controlador com os valores de corrente média na saída da fonte.

Na Tabela 3 são mostrados os principais valores dos parâmetros de soldagem utilizados para a realização experimental do presente trabalho. A energia de soldagem foi de $349 \mathrm{~J} / \mathrm{mm}$, calculada através da Equação 1. Devido não se ter um sistema de aquisição de dados no local da soldagem, não foi possível utilizar a Equação 2, que seria a forma correta no cálculo para arco pulsado (conceito de Potência Instantânea do arco) [16].

$E=\frac{V_{m} \times I_{m}}{v}$

$E=\frac{P_{\text {inst }}}{v}=\frac{\frac{\left(\sum V_{i} \times I_{i}\right)}{n}}{v}$

Sendo: $E=$ Energia de soldagem $(\mathrm{J} / \mathrm{mm}) ; V_{m}=$ Tensão média $(\mathrm{V}) ; I_{m}=$ Corrente média (A); $v=$ Velocidade linear de soldagem $(\mathrm{mm} / \mathrm{s}) ; V_{i}=$ Tensão instantânea $(\mathrm{V}) ; I_{i}=$ Corrente instantânea (A); $n=$ número de vezes que foram feitas as leituras de $V_{i}$ e $I_{i}$.

Tanto no tecimento "Triangular" quanto no "Vai-Vem", utilizou-se amplitude de movimento de $2,5 \mathrm{~mm}$ e frequência de $4 \mathrm{~Hz}$ para a realização do cordão de solda.

Recomenda-se que a tocha seja conduzida mantendo-se uma distância do bocal até a peça de 12 a $15 \mathrm{~mm}$, normalmente sendo inclinada no sentido "empurrando", com um ângulo de 5 a $15^{\circ}$ com a vertical, melhorando a molhabilidade [2]. Porém no presente trabalho adotou-se um ângulo da tocha de $90^{\circ}$ devido 
Tabela 3 - Resumo dos parâmetros de soldagem.

\begin{tabular}{|l|c|}
\hline \multicolumn{2}{|c|}{ Resumo dos paràmetros de soldagem utilizados } \\
\hline Corrente média & $140 \mathrm{~A}$ (argumento 2,4$)$ \\
\hline Tensão média & $20,4 \mathrm{~V}$ \\
\hline Velocidade de soldagem & $49 \mathrm{~cm} / \mathrm{min}(8,2 \mathrm{~mm} / \mathrm{s}$ ) \\
\hline Diståncia do bocal até a peça & $13 \mathrm{~mm}$ \\
\hline Ángulo da tocha & $90^{\circ}$ \\
\hline Vazão de gás (argőnio) & $13 \mathrm{Vmin}$ \\
\hline Energia de soldagem & $349 \mathrm{~J} / \mathrm{mm}$ \\
\hline
\end{tabular}

não se ter verificado nenhuma irregularidade motivada por essa técnica durante a soldagem.

Para a medição tridimensional, os pontos foram demarcados $15 \mathrm{~mm}$ um em relação ao outro, ao longo do perímetro das PTs. Para facilitar a análise dos dados, foram definidas três vistas: Vista 1 - perpendicular ao cordão de solda, ao longo da largura da PT, onde se inicia o processo (visualização da distorção angular transversal no início da soldagem); Vista 2 paralela ao cordão de solda, ao longo do comprimento da PT (visualização da flexão longitudinal); Vista 3 - perpendicular ao cordão de solda, ao longo da largura da PT, onde se finaliza o processo (visualização da distorção angular transversal no final da soldagem), gerando um total de 67 pontos. A Figura 4 mostra a esquematização do método.

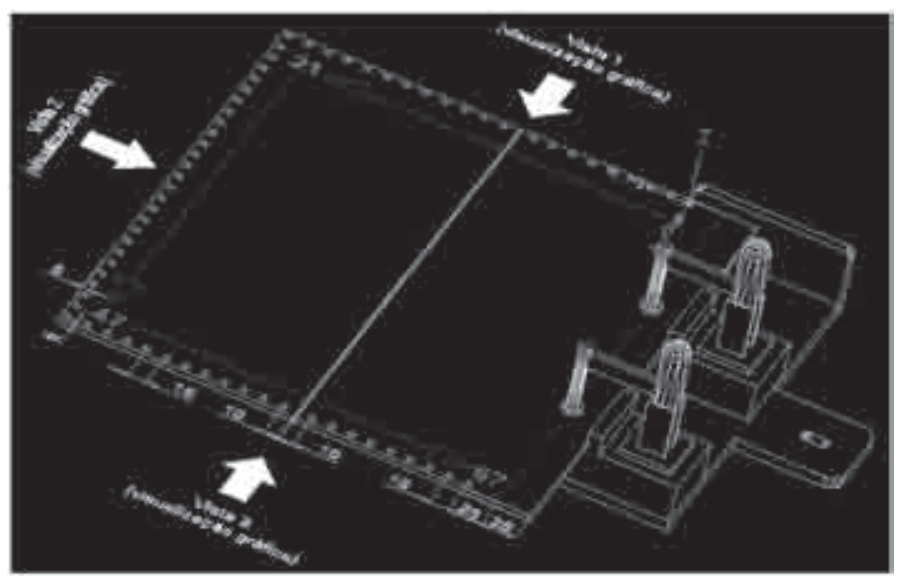

Figura 4 - Esquematização da sequência de medição dos pontos.

Através do braço 3D, foi medida a altura destes pontos em relação a um plano padrão tirado no gabarito nas duas bases de apoio das PTs, com o intuito de se obter a distorção real que as PTs sofreram, sendo esse o nivelamento adotado para todas as medições. Ou seja, considerou-se apenas a coordenada cartesiana Z, obtida pela medição do ponto em relação ao plano padrão.

A medição dos pontos foi realizada antes $\left(Z_{\text {Iniciat-Ponto }}\right)$ e após a soldagem $\left(Z_{\text {Final-Ponto }}\right)$, conforme a Equação 3, gerando assim a quantificação das distorções angulares reais, pois as PTs já apresentavam deformações antes da soldagem geradas principalmente pelo corte por guilhotina, pelo próprio processo de fabricação das chapas e pelo ponteamento.

$$
\Delta Z_{\text {Ponto }}=Z_{\text {Final_Ponto }}-Z_{\text {Inicial_Ponto }}
$$

Tendo esses valores coletados e calculados, gerou-se um gráfico para cada uma das três vistas (mostradas na Figura 4) em cada uma das PTs, facilitando a visualização e interpretação das distorções. Na sequência foi calculada a amplitude da distorção para cada uma das vistas em cada uma das PTs, segundo a Equação 4.

$$
\text { Amplitude }=\left|\Delta Z_{\text {Ponto_max }}-\Delta Z_{\text {Ponto_min }}\right|
$$

Comparou-se então estatisticamente as amplitudes das distorções, primeiramente de maneira individual na junta 1 e 2, finalizando na sequência junta $1 \mathrm{X}$ junta 2 . O software Excel 2007 foi utilizado para tal finalidade, em especifico as ferramentas de Análise de Dados Anova: Fator Único, e Anova: Fator Duplo com Repetição. Segundo Levine, Berenson e Stephan [17], o termo análise de variância (ou Anova) parece ser um nome mal aplicado, uma vez que o objetivo é analisar diferenças entre as médias aritméticas. No entanto, a partir de uma análise na variação dos dados, entre ou dentro dos grupos em estudo, pode-se tirar conclusões sobre possíveis diferenças nas médias dos grupos.

Como premissas para a o teste de hipóteses, deve-se definir as Hipóteses $\left(\mathrm{H}_{\mathrm{o}}\right.$ e $\left.\mathrm{H}_{1}\right)$ e o Nível se Significância $(\alpha)$. Tradicionalmente, os pesquisadores têm selecionado os níveis de $\alpha$ em 0,05 (5\%) ou menos. O teste de hipóteses consiste em verificar se as médias dos resultados dentro do planejamento são estatisticamente iguais ou diferentes, bem como verificar se há interação entre essas variáveis. Para avaliar as distorções, foram consideradas três variáveis de influência: o tipo de junta, o tipo de tecimento e a direção de soldagem em relação ao sentido de laminação da PT. A variável de resposta analisada foi a distorção na PT, quantificada através das amplitudes das distorções em cada vista.

Para cada PT soldada foram extraídas duas amostras para realização de exames macrograficos, em prática metalografica convencional e utilizando o reagente de Tucker (ácido fluorídrico $15 \mathrm{ml}$, clorídrico $45 \mathrm{ml}$, nítrico $15 \mathrm{ml}$ e água $25 \mathrm{ml}$ ), na temperatura ambiente e ataque por imersão. $\mathrm{O}$ dimensionamento do corpo de prova $(\mathrm{CP})$ para ensaio de tração foi baseado na norma AWS D1.2 [14].

\section{Resultados e Discussão}

Duas foram as formas como as distorções angulares apareceram em uma mesma PT: transversal "perfil parabólico com concavidade para baixo" e longitudinal "perfil parabólico com concavidade para cima" (Figuras 5 e 6); ou transversal "perfil parabólico com concavidade para cima" e longitudinal "perfil parabólico com concavidade para baixo" (Figuras 7 e 8). 


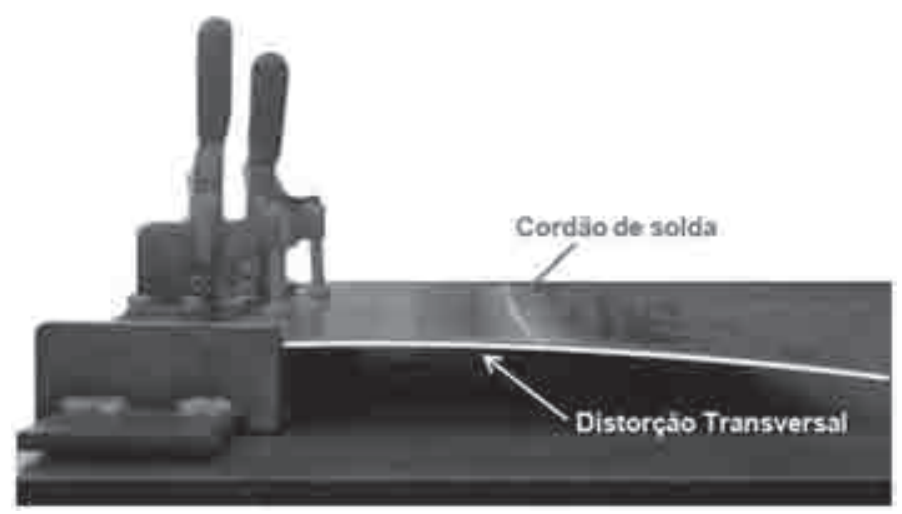

Figura 5 - Distorção transversal "perfil parabólico com concavidade para baixo".

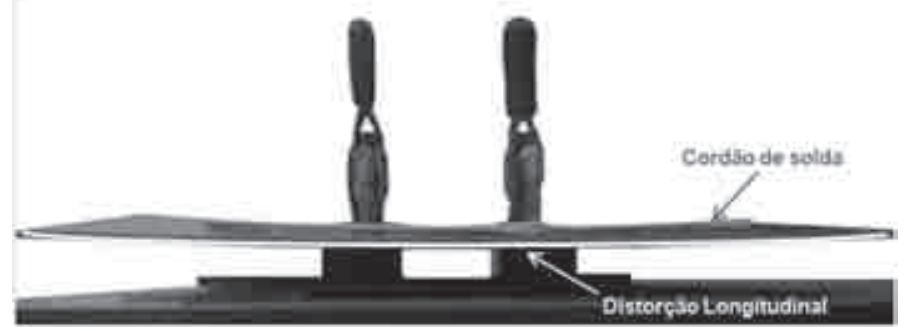

Figura 6 - Distorção longitudinal "perfil parabólico com concavidade para cima".

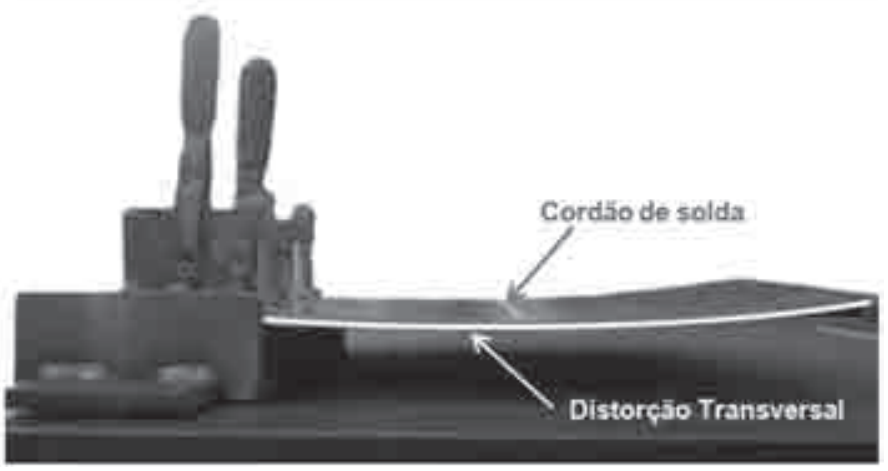

Figura 7 - Distorção transversal "perfil parabólico com concavidade para cima".

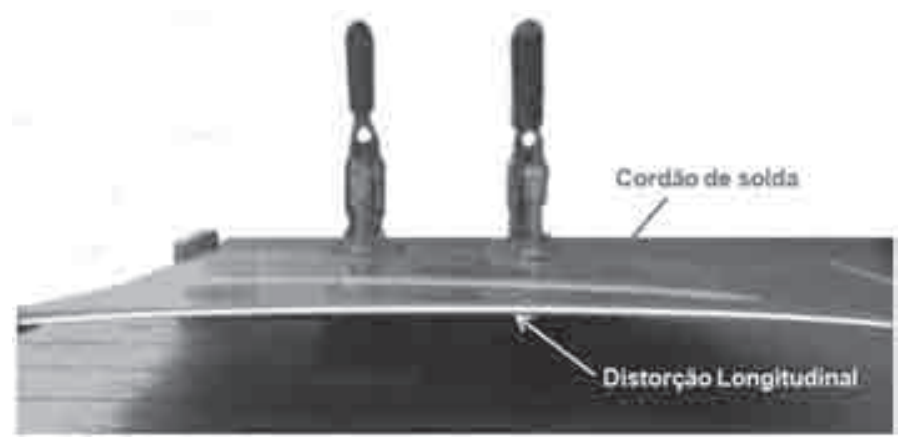

Figura 8 - Distorção longitudinal "perfil parabólico com concavidade para baixo".
O perfil do cordão de solda foi o fator determinante para as formas das distorções, conforme revelado pelas macrografias.

As placas de teste com a maior parte da área transversal de metal fundido abaixo da linha média (no sentido da espessura) apresentaram as distorções mostradas nas Figuras 5 e 6 . Esse tipo de distorção só foi verificado em algumas PTs da junta 1. A Figura 9 (a) e (b) mostra, respectivamente, uma macrografia realizada na PTLR2 e PTL3, e a exemplificação da quantificação das áreas, em porcentagem, acima e abaixo da linha média.

As placas de teste com a maior parte da área transversal de metal fundido acima da linha média (no sentido da espessura) apresentaram as distorções mostradas nas Figuras 7 e 8 . A Figura 10 (a) e (b) mostra, respectivamente, uma macrografia realizada na PTT10 e PTL8, e a exemplificação da quantificação das áreas, em porcentagem, acima e abaixo da linha média.

Considerou-se área transversal de metal fundido como sendo a área transversal formada pelo metal de solda depositado e a zona de fusão (ZF). A quantificação da área transversal de metal fundido foi realizada no software AutoCAD 2002, através da reprodução dessa área (criação de polyline) sobre a própria macrografia, e posterior cálculo de áreas.

Distorções angulares transversais e longitudinais, como mostradas nas Figuras 7 e 8, foram encontradas por Fraga [10] no estudo em questão, onde foi adotada como penetração mínima 2/3 da espessura da chapa, na soldagem TIG autógena sobre chapa, evidenciando que a área transversal de metal fundido com relação a linha média da espessura é o fator determinante para os sentidos das distorções angulares formadas.
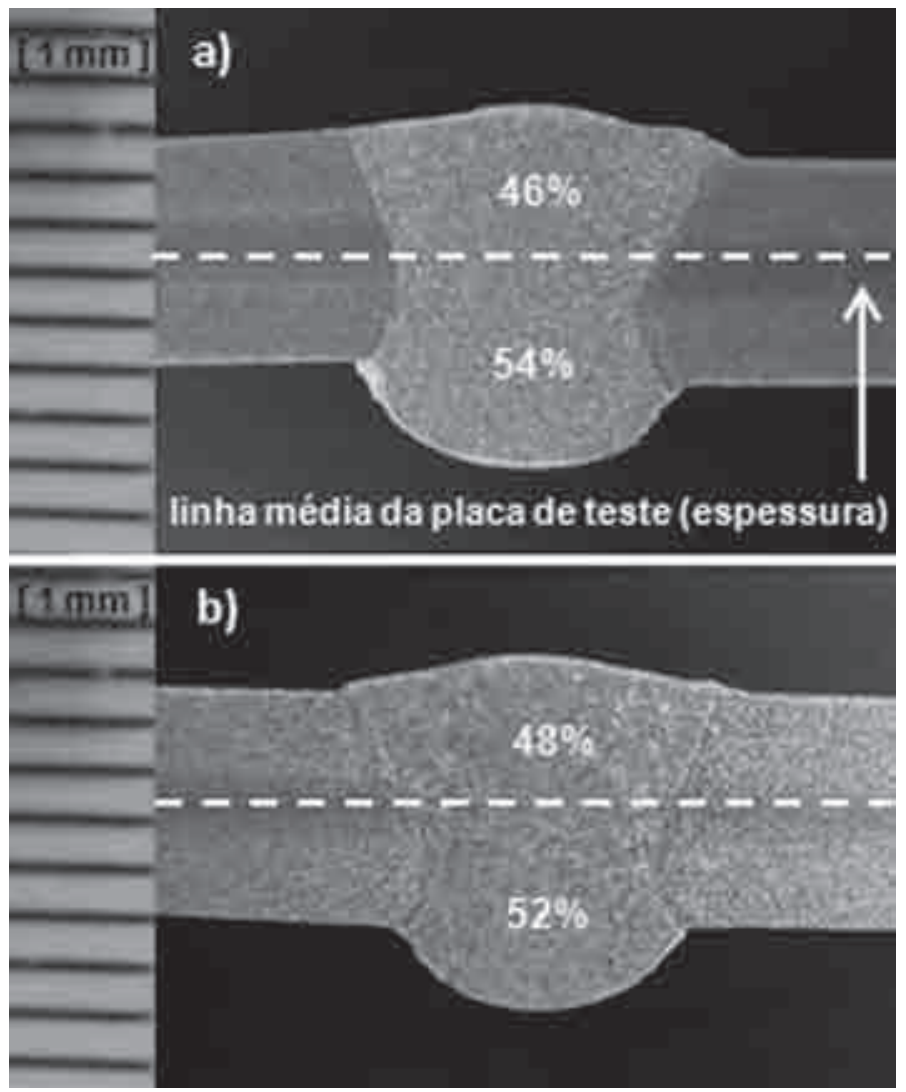

Figura 9 - Macrografias realizadas no: a) PTLR2 e b) PTL3. 


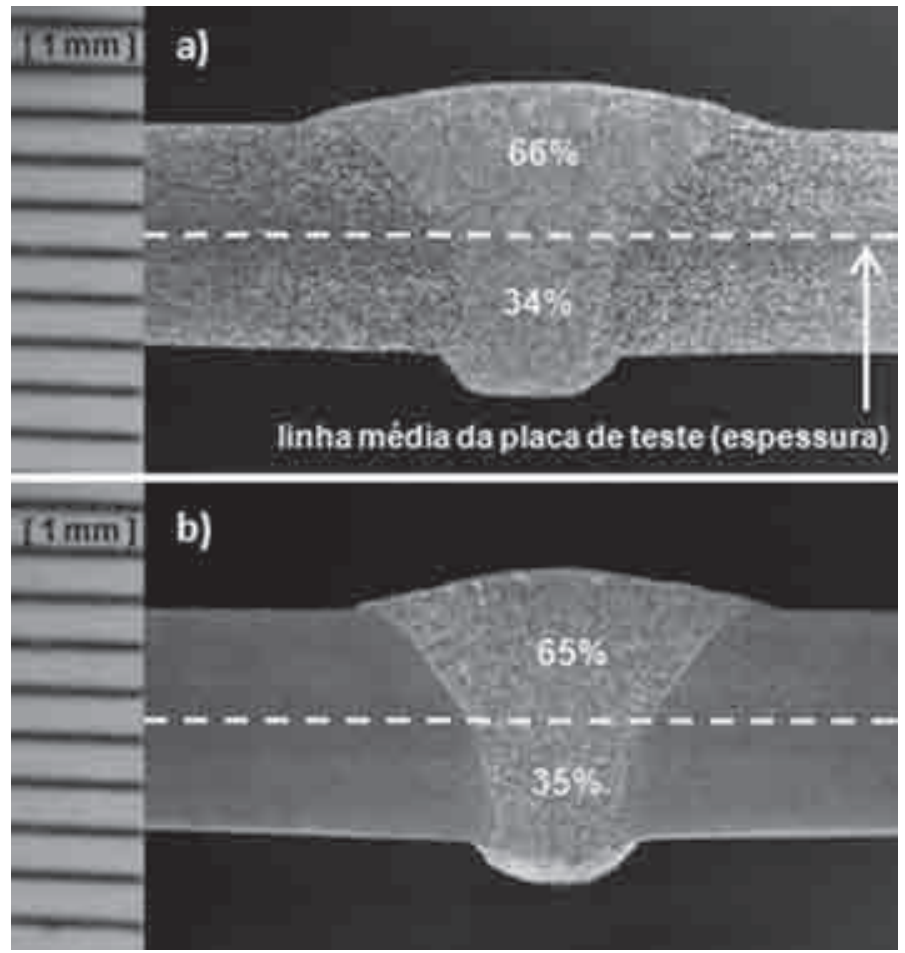

Figura 10 - Macrografias realizadas no: a) PTT10 e b) PTL8.

\subsection{Placas de teste sem chanfro (junta 1)}

As PTs sem chanfro apresentaram os dois tipos de formas de distorções transversais e longitudinais: 11 PTs apresentaram

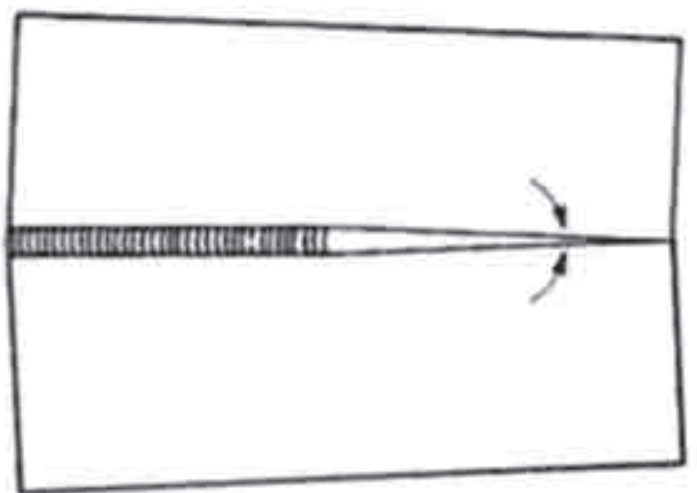

\section{a) Porçöes não-soldadas da junta se fecham (soldagem com eletrodo revestido)}

distorção transversal "perfil parabólico com concavidade para baixo" e longitudinal "perfil parabólico com concavidade para cima" (Figuras 5 e 6) e 8 PTs apresentaram distorção transversal "perfil parabólico com concavidade para cima" e longitudinal "perfil parabólico com concavidade para baixo" (Figuras 7 e 8).

A dificuldade para manutenção de um cordão com características mais regulares de penetração no decorrer da soldagem foi maior para esse tipo de junta, gerando os dois sentidos de deformações descritos no parágrafo anterior. As possíveis causas para essa ocorrência são as seguintes: pequenas variações na montagem da junta (abertura entre chapas); alguns problemas encontrados com relação ao fluxo do gás de proteção durante o início experimento (solenóide do cabeçote); energia de soldagem relativamente alta para esse tipo de junta em passe único, porém foram adotados os mesmos parâmetros de soldagem para os dois tipos de junta, sendo que a junta 2 teve uma penetração mais uniforme devido sua própria configuração geométrica.

Evidenciou-se também distorção rotacional nas PTs da junta 1, durante a fase de testes, idêntica à mostrada na Figura 11 (a). A abertura de 1,4 mm entre as chapas se mostrou apropriada para evitar esse tipo de distorção durante a soldagem, além do ponteamento realizado.

As Figuras de 12 a 14 mostram os gráficos das distorções nas três vistas para a condição sem tecimento.

A Tabela 4 mostra os valores das amplitudes das distorções entre PTTs e PTLs na condição sem tecimento. Também foi salientado em negrito os valores das maiores e menores amplitudes encontradas.

Figura 11 - Variação dimensional rotacional em uma junta de topo: (a) soldagem com eletrodo revestido; e (b) soldagem a arco submerso (Adaptado de AWS [13]). 


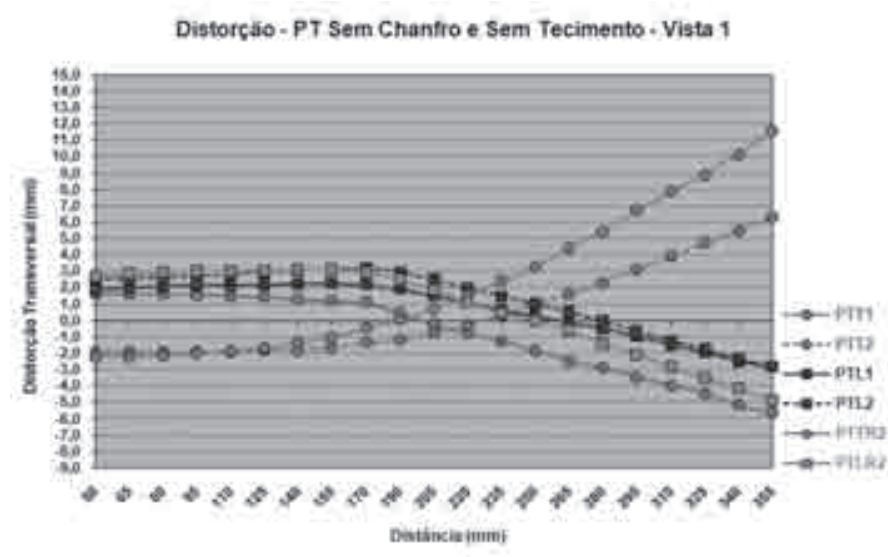

Figura 12 - Distorção vista 1, PT sem chanfro (junta 1) e sem tecimento.

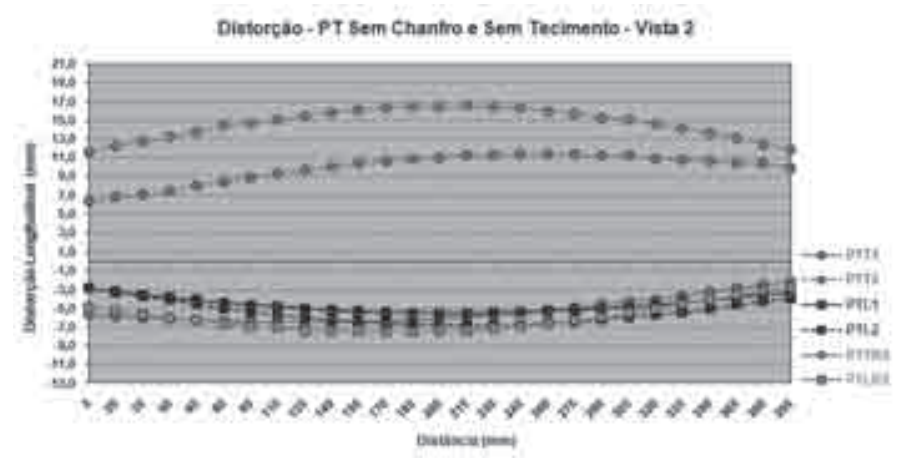

Figura 13 - Distorção vista 2, PT sem chanfro (junta 1) e sem tecimento.

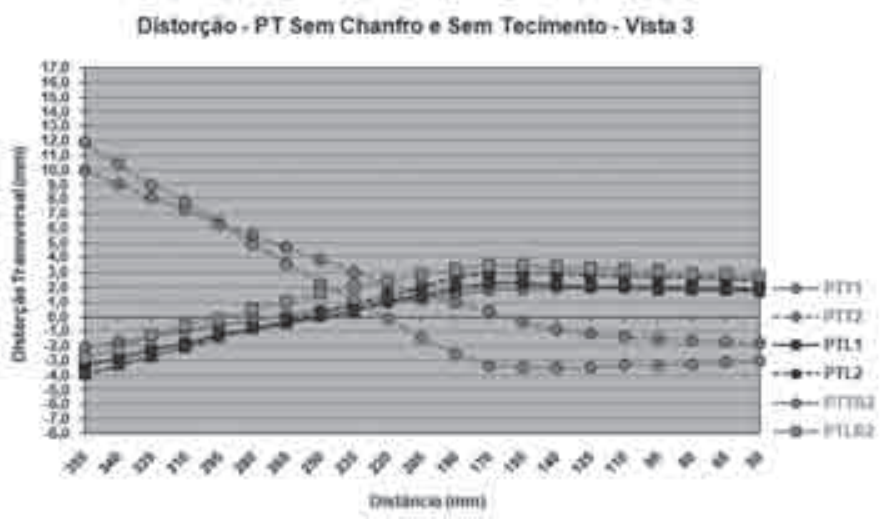

Figura 14 - Distorção vista 3, PT sem chanfro (junta 1) e sem tecimento.

A Tabela 5 mostra a saída dos resultados gerada pelo Excel para análise das amplitudes das distorções entre as PTTs e PTLs na condição sem tecimento, utilizando a ferramenta Anova: Fator Único. Segundo Costa Neto [18], quando F < F crítico, escolhe-se $\mathrm{H}_{0}$. Quando $\mathrm{F}>\mathrm{F}$ crítico, escolhe-se $\mathrm{H}_{1}$. $\mathrm{O}$ nível de significância adotado, para essa análise e de todas as outras, foi de $0,05(5 \%)$.

As hipóteses adotadas, para análise individual de cada tipo de tecimento, foram:

- $\mathrm{H}_{02}\left(\mu_{\mathrm{PTT}}=\mu_{\mathrm{PTL}}\right)-\mathrm{O}$ sentido de laminação da chapa em relação ao cordão de solda não é uma variável de influência estatisticamente significativa nas médias das amplitudes das distorções.

- $\mathrm{H}_{12}\left(\mu_{\mathrm{PTT}} \neq \mu_{\mathrm{PTL}}\right)-\mathrm{O}$ sentido de laminação da chapa em relação ao cordão de solda é uma variável de influência estatisticamente significativa nas médias das amplitudes das distorções.

Verificou-se na Tabela 5 que o valor de F $(3,2692)$ é menor que $\mathrm{F}$ crítico $(4,4940)$, logo se pode admitir que o sentido de laminação da chapa em relação ao cordão de solda não é uma variável de influência estatisticamente significativa nas médias das amplitudes das distorções $\left(\mathrm{H}_{02}\right)$ na condição sem tecimento.

Resultados estatísticos similares aos mostrados para a condição sem tecimento foram encontrados para os tecimentos "Triangular" e "Vai-Vem" na junta 1, utilizando a mesma sequência de análise.

\subsubsection{Análise global das placas de teste sem chanfro (junta 1)}

Para análise global das amplitudes das distorções encontradas nas PTs com junta sem chanfro, utilizou-se a ferramenta Anova: Fator Duplo com Repetição. A construção das hipóteses para esse caso deve levar em consideração a possível interação entre os três tipos de tecimento e os dois sentidos de laminação das chapas em relação ao cordão de solda, agrupados de maneira global. As hipóteses adotadas para esse tipo de análise foram:

* Interações das variáveis:

- $\mathrm{H}_{0}$ - As interações das variáveis não geram influência estatisticamente significativa nas médias das amplitudes das distorções.

- $\mathrm{H}_{1}$ - As interações das variáveis geram influência estatisticamente significativa nas médias das amplitudes das distorções.

* Tipos de tecimento:

- $\mathrm{H}_{01}-\mathrm{O}$ tipo de tecimento não é uma variável de influência estatisticamente significativa nas médias das amplitudes das distorções.

- $\mathrm{H}_{11}$ - O tipo de tecimento é uma variável de influência estatisticamente significativa nas médias das amplitudes das distorções.

* Sentido de laminação da chapa em relação ao cordão de solda:

- $\mathrm{H}_{02}$ - $\mathrm{O}$ sentido de laminação da chapa em relação ao cordão de solda não é uma variável de influência estatisticamente significativa nas médias das amplitudes das distorções.

- $\mathrm{H}_{12}$ - $\mathrm{O}$ sentido de laminação da chapa em relação ao cordão de solda é uma variável de influência estatisticamente significativa nas médias das amplitudes das distorções.

A Tabela 6 mostra a saída dos resultados gerada pelo Excel para análise das amplitudes das distorções nas PTs da junta1. Nela foi possível verificar que:

- Para as interações das variáveis, o valor de F (0,0449) é menor que $\mathrm{F}$ crítico $(3,1907)$, logo as interações das variáveis não geram influência estatisticamente significativa nas médias das amplitudes das distorções nas PTs da junta $1\left(\mathrm{H}_{0}\right)$;

- Para os tipos de tecimento, o valor de F $(0,3670)$ é menor que F crítico $(3,1907), \log$ o o tipo de tecimento não é uma variável 
Tabela 4 - Amplitudes das distorções entre PTTs e PTLs na condição sem tecimento, junta 1.

\begin{tabular}{|c|c|c|c|c|c|c|c|c|c|}
\hline \multicolumn{10}{|c|}{ Sem tecimento - Junta sem chanfro } \\
\hline \multicolumn{2}{|c|}{ PTT } & \multirow{2}{*}{$\frac{\Delta Z_{\text {rorme } \max }(\mathrm{mm})}{1,648}$} & \multirow{2}{*}{$\frac{\Delta Z_{\text {:orme_min }}(\mathrm{mm})}{-5,660}$} & \multicolumn{2}{|c|}{ Amplitude (mm) } & \multirow{2}{*}{$\frac{\Delta z_{\text {Poendmin }}(\mathrm{mm})}{-2,858}$} & \multirow{2}{*}{$\frac{\Delta \mathrm{Z}_{\text {Fente } \max }(\mathrm{mm})}{2,261}$} & \multicolumn{2}{|c|}{ PTL } \\
\hline \multirow{3}{*}{ PII1 } & Vista 1 & & & 7,308 & 5,119 & & & Vista 1 & \multirow{3}{*}{ PTL1 } \\
\hline & Vista 2 & $-2,127$ & $-6,449$ & 4,322 & 2,678 & $-5,536$ & $-2,858$ & Vista 2 & \\
\hline & Vista 3 & 2,005 & $-2,127$ & 4,132 & 5,616 & $-3,316$ & 2,300 & Vista 3 & \\
\hline \multirow{3}{*}{ PT12 } & Vista 1 & 6,286 & $-1,964$ & 8,250 & 6,048 & $-2,827$ & 3,221 & Vista 1 & \multirow{3}{*}{ PTL2 } \\
\hline & Vista 2 & 11,449 & 6,771 & 4,678 & 3,995 & $-6,822$ & $-2,827$ & Vista 2 & \\
\hline & $\overline{V i s t a ~} 3$ & 9,963 & $-1,834$ & 11,797 & 6,966 & 3,966 & 3,000 & Vista 3 & \\
\hline \multirow{3}{*}{ PTTR2 } & Vista 1 & 11,629 & $-2,231$ & 13,860 & 7,986 & $-4,884$ & 3,102 & Vista 1 & \multirow{3}{*}{ PTLR2 } \\
\hline & Vista 2 & 16,522 & 11,629 & 4,893 & 4,699 & $-7,504$ & $-2,805$ & Vista 2 & \\
\hline & $\longdiv { \text { Vista } 3 }$ & 11,899 & $-3,480$ & 15.379 & 6,324 & $-2,805$ & 3,519 & $\sqrt{\text { Vista } 3}$ & \\
\hline
\end{tabular}

Tabela 5 - Anova: Fator Único. Saída de dados para análise das amplitudes das distorções entre PTTs e PTLs na condição sem tecimento, junta 1.

RESUMO

\begin{tabular}{lrrrrr}
\hline Grupo & Contagem & Soma & Média & Variância Desvio Padrão \\
\hline Amplitude PTT $(\mathrm{mm})$ & 974,6190 & 8,2910 & 19,0205 & 4,3612 \\
Amplitude PTL $(\mathrm{mm})$ & 949,4310 & 5,4923 & 2,5421 & 1,5944 \\
\hline
\end{tabular}

ANOVA

\begin{tabular}{|c|c|c|c|c|c|c|}
\hline Fonte da variação & $S Q$ & $g l$ & $M Q$ & $F$ & valor-P & Fcrítico \\
\hline Entre grupos & 35,2464 & 1 & 5,2464 & 3,2692 & 0,0894 & 4,4940 \\
\hline Dentro dos grupos & 172,5010 & 16 & 0,7813 & & & \\
\hline
\end{tabular}

Total

207,7474

17

de influência estatisticamente significativa nas médias das amplitudes das distorções nas PTs da junta $1\left(\mathrm{H}_{01}\right)$;

- Para o sentido de laminação da chapa em relação ao cordão de solda, o valor de F $(8,5546)$ é maior que F crítico $(4,0427)$, logo o sentido de laminação da chapa em relação ao cordão de solda é uma variável de influência estatisticamente significativa nas médias das amplitudes das distorções nas PTs da junta $1\left(\mathrm{H}_{12}\right)$.

Porém a aceitação da hipótese $\mathrm{H}_{12}$ não deve ser interpretada rigorosamente, pois o principal motivo que levou a esse resultado foi a grande dispersão na medição dos pontos $\left(\Delta Z_{\text {ponto }}\right)$, gerada pelas duas formas das distorções, tanto transversais quanto longitudinais, que foram encontradas nas placas de teste da junta 1 , e não propriamente o sentido de laminação da chapa em relação ao cordão de solda.
Como forma de quantificar as distorções e fazer os testes de hipóteses, adotou-se as amplitudes destas em cada vista das PTs, visando diminuir a influência da dispersão na medição dos pontos gerada pelas diferentes formas das distorções encontradas nas PTs da junta 1.

Verifica-se também que, mesmo tendo ocorrido o descrito acima, as PTTs sempre mantiveram as médias das amplitudes das distorções maiores que as PTLs (tendência), assim como mostrado na Tabela 6. Foram realizados ensaios de tração em corpos de prova retirados no metal base, transversal e longitudinalmente ao sentido de laminação da chapa, para analisar se o limite de escoamento teria alguma influência na tendência encontrada, porém nenhuma diferença foi verificada. A Tabela 7 mostra os limites de escoamento obtidos nos ensaios de tração. 
Tabela 6 - Anova: Fator Duplo com Repetição. Saída de dados para a análise de variância global dos resultados das amplitudes das distorções nas PTs com junta sem chanfro (junta 1).

\begin{tabular}{lrrr}
$\begin{array}{l}\text { RESUMO } \\
\text { Sem teciphento }\end{array}$ & PTT & PTL & Total \\
\hline Contagem & 9 & 9 & 18 \\
Sorna & 74,6190 & 49,4310 & 124,0500 \\
Media & 8,2810 & 5,4923 & 6,8917 \\
Variància & 19,0205 & 2,5421 & 12,2204
\end{tabular}

Tecimento Zig-Zog"

\begin{tabular}{lrrr}
\hline Contagem & 9 & 9 & 18 \\
Soma & 79,7640 & 59,8080 & 139,5720 \\
Mèdia & 8,8627 & 6,6453 & 7,7540 \\
Variancia & 11,0437 & 13,2878 & 12,7516
\end{tabular}

Teamento Vor-Vern"

\begin{tabular}{|c|c|c|c|c|c|c|}
\hline Contagem & 9 & 9 & 18 & & & \\
\hline Soma & 75,6160 & 50,7680 & 126,3840 & & & \\
\hline Médta & 8,4018 & 3,6409 & 7,0213 & & & \\
\hline Variância & 14,2212 & 3,5135 & 10,3635 & & & \\
\hline \multicolumn{7}{|l|}{ Total } \\
\hline Contagem & 27 & 27 & & & & \\
\hline Soma & 229,9990 & 160,0070 & & & & \\
\hline Media & 8,5185 & 5,9262 & & & & \\
\hline Variância & 13,6899 & 6,2242 & & & & \\
\hline Desvio Padrâo & 3,7000 & 2,4948 & & & & \\
\hline \multicolumn{7}{|l|}{ ANOVA } \\
\hline Fonte da variaçäo. & sa & g! & $M Q$ & $F$ & valor-p & Fentico \\
\hline Tecimento & 7,7834 & 2 & 3,8917 & 0,3670 & 0,6948 & 3,1907 \\
\hline $\mathrm{prT} / \mathrm{PTL}$ & 90,7200 & 1 & 90,7200 & 8,5546 & 0,0052 & 4,0427 \\
\hline Interaçōes: & 0,9522 & 2 & 0,4761 & 0,0499 & 0,9561 & 3,1907 \\
\hline Dentro & 509,0308 & 48 & 10,6048 & & & \\
\hline Total & 608,4865 & 53 & & & & \\
\hline
\end{tabular}

Tabela 7 - Limite de escoamento, em MPa, dos CPs retirados do metal base.

\begin{tabular}{|c|c|c|}
\hline Amostra & $\begin{array}{c}\text { Corpo de prova } \\
\text { longitudinal }\end{array}$ & $\begin{array}{c}\text { Corpo de prova } \\
\text { transversal }\end{array}$ \\
\hline 1 & 182,1 & 195,0 \\
\hline 2 & 192,3 & 185,9 \\
\hline 3 & 191,8 & 195,6 \\
\hline 4 & 184,2 & 196,8 \\
\hline 5 & 195,5 & 189,5 \\
\hline 6 & 193,7 & 188,4 \\
\hline 7 & 186,4 & 184,0 \\
\hline Média (MPa) & 189,4 & 190,7 \\
\hline Desvio padrão(MPa) & 5,2 & 5,1 \\
\hline
\end{tabular}

\subsection{Placas de teste com chanfro $60^{\circ}$ (junta 2 )}

As 19 PTs com chanfro $60^{\circ}$ (junta 2) apresentaram apenas uma forma de distorção (Figuras 7 e 8). Isso mostra que a distorção nesse tipo de junta sempre manteve uma mesma tendência, devido à maior parte da área transversal de metal fundido acima da linha média (no sentido da espessura), sendo que nesse aspecto o próprio formato da junta chanfrada facilita.

As Figuras de 15 a 17 mostram os gráficos das distorções nas três vistas para a condição sem tecimento.

A Tabela 8 mostra os valores das amplitudes das distorções entre PTTs e PTLs na condição sem tecimento. Também foi salientado em negrito os valores das maiores e menores amplitudes encontradas.

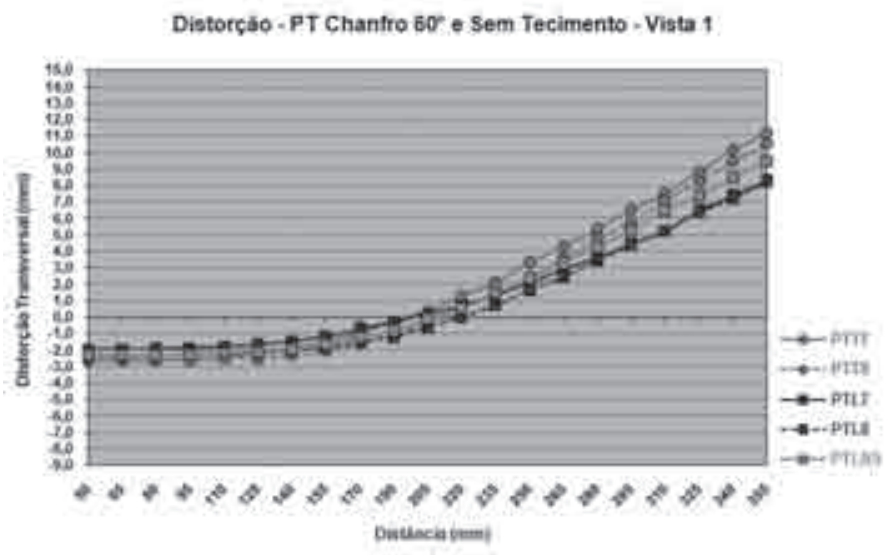

Figura 15 - Distorção vista 1 , PT chanfro $60^{\circ}$ (junta 2 ) e sem tecimento.

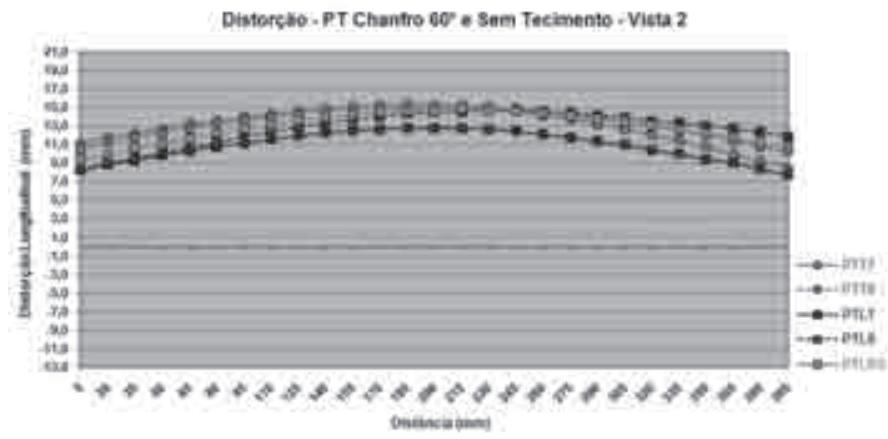

Figura 16 - Distorção vista 2, PT chanfro $60^{\circ}$ (junta 2) e sem tecimento.

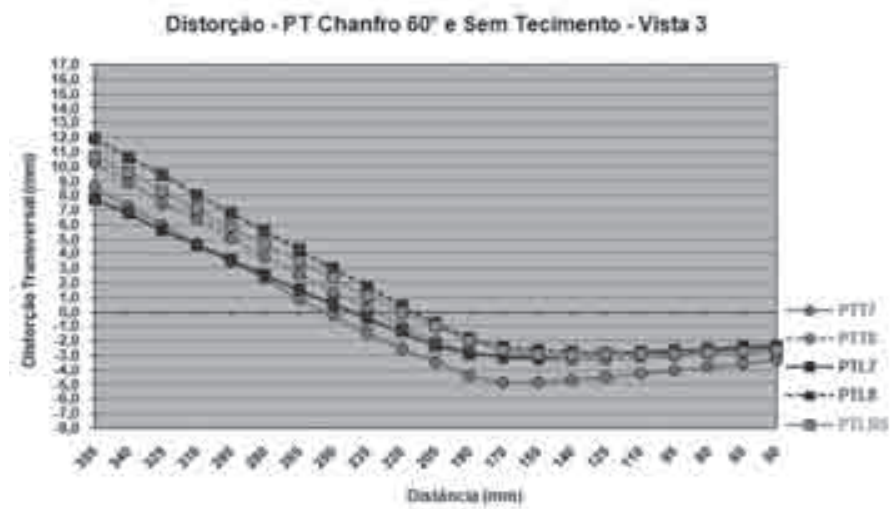

Figura 17 - Distorção vista 3 , PT chanfro $60^{\circ}$ (junta 2) e sem tecimento. 
Tabela 8 - Amplitudes das distorções entre PTTs e PTLs na condição sem tecimento, junta 2.

\begin{tabular}{|c|c|c|c|c|c|c|c|c|c|}
\hline \multicolumn{10}{|c|}{ Sem tecimento - Junta chanfro $60^{\circ}$} \\
\hline \multicolumn{2}{|c|}{ PTा } & \multirow{2}{*}{$\frac{\Delta z_{\text {ponto,max }}(\mathrm{mm})}{11,172}$} & \multirow{2}{*}{$\frac{\Delta Z_{\text {Porte } m n}(\mathrm{~mm})}{-2,641}$} & \multicolumn{2}{|c|}{ Amplitude (mm) } & \multirow{2}{*}{\begin{tabular}{|c|}
$\Delta Z_{\text {Ponto_min }}(\mathrm{mm})$ \\
$-1,958$ \\
\end{tabular}} & \multirow{2}{*}{$\frac{\Delta z_{\text {Ponto__max }}(\mathrm{mm})}{8,271}$} & \multicolumn{2}{|c|}{ PTL } \\
\hline \multirow{3}{*}{ PTT7 } & Vista 1 & & & 13,813 & 10,229 & & & Vista 1 & \multirow{3}{*}{ PTL7 } \\
\hline & Vista 2 & 15,192 & 8,538 & 6,654 & 5,050 & 7,762 & 12,812 & Vista 2 & \\
\hline & Vista 3 & 8,538 & $-4,903$ & 13,441 & 10,880 & $-3,118$ & 7,762 & Vista 3 & \\
\hline \multirow{3}{*}{ PTा8 } & Vista 1 & 10,492 & $-2,620$ & 13,112 & 10,608 & $-2,305$ & 8,303 & Vista 1 & \multirow{3}{*}{ PTL8 } \\
\hline & Vista 2 & 15,316 & 8,876 & 6,440 & 6,392 & 8,303 & 14,695 & Vista 2 & \\
\hline & Vista 3 & 10,267 & $-3,315$ & 13,582 & 14,736 & $-2,814$ & 11,922 & Vista 3 & \\
\hline \multirow{3}{*}{ - } & 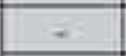 & - & - & - & 11,808 & $-2,327$ & 9,481 & Vista 1 & \multirow{3}{*}{ PTLR5 } \\
\hline & - & - & - & - & 5,366 & 9,481 & 14,847 & Vista 2 & \\
\hline & $=$ & - & - & - & 13,756 & $-3,031$ & 10,725 & Vista 3 & \\
\hline
\end{tabular}

Tabela 9 - Anova: Fator Único. Saída de dados para análise das amplitudes das distorções entre PTTs e PTLs na condição sem tecimento, junta 2.

\begin{tabular}{lrlrrr}
\hline Grupo & Contagem & Soma & Média & Variância & Desvio Padrão \\
\hline Amplitude PTT $(\mathrm{mm})$ & 6 & 67,0420 & 11,1737 & 12,8998 & 3,5916 \\
Amplitude PTL $(\mathrm{mm})$ & 9 & 88,8250 & 9,8694 & 12,4804 & 3,5328 \\
\hline
\end{tabular}

\section{ANOVA}

\begin{tabular}{|c|c|c|c|c|c|c|}
\hline Fonte da variaçẫo & $S Q$ & $g l$ & $M Q$ & $F$ & valor-P & Fcrítico \\
\hline Entre grupos & 6,1236 & 1 & 6,1236 & 0,4844 & 0,4987 & 4,6672 \\
\hline Dentro dos grupos & 164,3424 & 13 & 12,6417 & & & \\
\hline
\end{tabular}

A Tabela 9 mostra a saída dos resultados gerada pelo Excel para análise das amplitudes das distorções entre as PTTs e PTLs na condição sem tecimento. Verificou-se que o valor de $\mathrm{F}$ $(0,4844)$ é menor que $\mathrm{F}$ crítico $(4,6672)$, logo se pode admitir que o sentido de laminação da chapa em relação ao cordão de solda não é uma variável de influência estatisticamente significativa nas médias das amplitudes das distorções $\left(\mathrm{H}_{02}\right)$ na condição sem tecimento.

Resultados estatísticos similares aos mostrados para a condição sem tecimento foram encontrados para os tecimentos "Triangular" e "Vai-Vem" na junta 2, utilizando a mesma sequência de análise.

\subsubsection{Análise global das placas de teste com chanfro $60^{\circ}$ (junta 2)}

As hipóteses adotadas para esse tipo de análise foram as mesmas adotadas para a junta 1 .
Para que seja possível utilizar a ferramenta Anova: Fator Duplo com Repetição, ao se analisar globalmente a junta 2, as amostras devem possuir números iguais de elementos, por isso as placas de teste reservas PTLR5 (sem tecimento) e PTTR4, PTTR5, PTTR6 e PTLR7 (tecimento "Triangular") foram desconsideradas, apesar de não se ter verificado nenhuma irregularidade na soldagem das mesmas. Porém nas análises individuais dos tipos de tecimento, foram consideradas todas as PTs.

A Tabela 10 mostra a saída dos resultados gerada pelo Excel para análise global das amplitudes das distorções nas PTs da junta 2. Nela foi possível verificar:

- Para as interações das variáveis, o valor de F $(0,2371)$ é menor que $\mathrm{F}$ crítico $(3,3158), \operatorname{logo}$ as interações das variáveis não geram influência estatisticamente significativa nas médias das amplitudes das distorções nas PTs da junta $2\left(\mathrm{H}_{0}\right)$;

- Para os tipos de tecimento, o valor de F $(0,0405)$ é menor que F crítico (3,3158), logo o tipo de tecimento não é uma variável 
de influência estatisticamente significativa nas médias das amplitudes das distorções nas PTs da junta $2\left(\mathrm{H}_{01}\right)$;

- Para o sentido de laminação da chapa em relação ao cordão de solda, o valor de F $(0,0220)$ é menor que F crítico $(4,1709)$, logo se pode admitir que o sentido de laminação da chapa em relação ao cordão de solda não é uma variável de influência estatisticamente significativa nas médias das amplitudes das distorções nas PTs da junta $2\left(\mathrm{H}_{02}\right)$.

Tabela 10 - Anova: Fator Duplo com Repetição. Saída de dados para a análise de variância global dos resultados das amplitudes das distorções nas PTs com junta chanfrada em $60^{\circ}$ (junta 2).

\begin{tabular}{lrrr}
$\begin{array}{l}\text { RESUMO } \\
\text { Sem tneimento }\end{array}$ & PTT & PTL & Total \\
\hline Contagem & 6 & 6 & 12 \\
Soma & 67,0420 & 57,8950 & 124,9370 \\
Médliil & 11,1737 & 9,6492 & 10,4114 \\
Variáncia & 12,8998 & 12,0816 & 11,9890
\end{tabular}

Tecimento Zgg-Zog"

\begin{tabular}{lrrr}
\hline Contagem & 6 & 6 & 12 \\
Soma & 62,9510 & 67,2630 & 130,2190 \\
Mầdia & 10,4918 & 11,2113 & 10,8516 \\
Variâncias & 21,0334 & 23,3946 & 20,3357
\end{tabular}

Tecimento Val-Vern:

\begin{tabular}{lrrr}
\hline Contagem & 6 & 6 & 12 \\
Soma & 64,2810 & 65,4010 & 129,6820 \\
Media & 10,7135 & 10,9002 & 10,8068 \\
Varialncia & 18,8392 & 16,0993 & 15,8906
\end{tabular}

Total

\begin{tabular}{lrr}
\hline Contagern & 18 & 18 \\
Sorna & 194,2740 & 190,5640 \\
Mèdia & 10,7930 & 10,5860 \\
Variảncia & 15,6067 & 15,6519 \\
Desvio Padräo & 3,9505 & 3,9562
\end{tabular}

ANOVA

\begin{tabular}{|c|c|c|c|c|c|c|}
\hline Fonte da varioģâo & $S Q$ & $g !$ & Ma & $f$ & valor-p & Fcribico \\
\hline Tecimerito & 1,4084 & 2 & 0,7042 & 0,0405 & 0,9604 & 3,3158 \\
\hline $\mathrm{pTT} / \mathrm{prL}$ & 0,3823 & 1 & 0,3823 & 0,0220 & 0,8831 & 4,1709 \\
\hline interaçöes & 8,2475 & 2 & 4,1238 & 0,2371 & 0,7904 & 3,3158 \\
\hline Dentro & 521.7396 & 30 & 17,3913 & & & \\
\hline Total & 531.7779 & 35 & & & & \\
\hline
\end{tabular}

\subsection{Comparação das distorções das placas de teste da junta $1 \mathrm{X}$ junta 2}

As hipóteses adotadas para esse tipo de análise foram as mesmas adotadas para os itens 3.1.1 e 3.2.1.

A Tabela 11 mostra as amplitudes das distorções para as PTs da junta 1 e junta 2 de maneira global. Para que seja possível utilizar a ferramenta Anova: Fator Duplo com Repetição, ao se analisar globalmente as juntas, as amostras devem possuir números iguais de elementos, por isso todas as placas de teste reservas (PTTR e PTLR) foram desconsideradas, apesar de não se ter verificado nenhuma irregularidade na soldagem das mesmas

A Tabela 12 mostra a saída dos resultados gerada pelo Excel para análise global das amplitudes das distorções nas PTs da junta 1 e 2. Nela se verificou:

- Para as interações das variáveis, o valor de F $(0,2456)$ é menor que $\mathrm{F}$ crítico $(2,2541), \operatorname{logo}$ as interações das variáveis não geram influência estatisticamente significativa nas médias das amplitudes das distorções nas PTs da junta 1 e junta $2\left(\mathrm{H}_{0}\right)$;

- Para os tipos de tecimento, o valor de F $(0,1790)$ é menor que F crítico $(3,1504)$, logo o tipo de tecimento não é uma variável de influência estatisticamente significativa nas médias das amplitudes das distorções nas PTs da junta 1 e junta $2\left(\mathrm{H}_{01}\right)$.

- Para o sentido de laminação da chapa em relação ao cordão, o valor de $\mathrm{F}(10,8678)$ é maior que $\mathrm{F}$ crítico $(2,7581)$, logo o sentido de laminação da chapa em relação ao cordão de solda é uma variável de influência estatisticamente significativa nas médias das amplitudes das distorções nas PTs da junta 1 e junta $2\left(\mathrm{H}_{12}\right)$.

Tabela 11 - Amplitudes das distorções das PTs da junta 1 e junta 2 .

\begin{tabular}{|c|c|c|c|c|}
\hline \multicolumn{5}{|c|}{ Amplitudes das distorcūes (mm) } \\
\hline \multirow{2}{*}{$\begin{array}{l}\text { Tipo de } \\
\text { Tecimento }\end{array}$} & \multicolumn{2}{|c|}{ Junta sem chantro (jurita 1) } & \multicolumn{2}{|c|}{ Junta chanfro $60^{\circ}$ (junta 2) } \\
\hline & PTT & PTL & PII & PTL \\
\hline \multirow{6}{*}{ Sern fecimento } & 7,308 & 5,119 & 13,813 & 10,229 \\
\hline & 4,322 & 2878 & 6,654 & 5.050 \\
\hline & 4,132 & 5,616 & 13,441 & 10,880 \\
\hline & 8,250 & 6,048 & 13,112 & 10,608 \\
\hline & 4.678 & 3,995 & 6,440 & 6,392 \\
\hline & 11,797 & 6,966 & 13.582 & 14,736 \\
\hline \multirow{6}{*}{ "Zig-Zag" } & 6,934 & 3,692 & 12,067 & 13,661 \\
\hline & 6,195 & 1,931 & 4,952 & 5,423 \\
\hline & 7.514 & 4,490 & 14,893 & 15,828 \\
\hline & 11,222 & 8,575 & 12,332 & 12,679 \\
\hline & 4,125 & 3,740 & 4,524 & 4.827 \\
\hline & 11,450 & 7,372 & 14,183 & 14,850 \\
\hline \multirow{6}{*}{ Va-Vern } & 7,428 & 6,083 & 12,109 & 9,369 \\
\hline & 4,532 & 3,591 & 4,349 & 6,941 \\
\hline & 7,668 & 6,851 & 13,628 & 14,639 \\
\hline & 8,736 & 7,695 & 11,698 & 11,169 \\
\hline & 4.472 & 4,718 & 6,682 & 6.777 \\
\hline & 8274 & 8,742 & 15,815 & 16,506 \\
\hline
\end{tabular}

O resultado já era esperado, uma vez que já havia sido verificada estatisticamente diferença nas médias das amplitudes das distorções entre os PTTs e PTLs da junta 1, quando a análise foi feita de maneira global.

Como não se verificou na junta 2 a mesma tendência encontrada na junta 1 , é possível afirmar que a dispersão de dados gerada pelas diferentes formas das distorções na junta 1 foi o fator determinante para o resultado encontrado, e não especificamente o sentido de laminação da chapa em relação ao cordão de solda. Uma maneira de se analisar se houve alguma variação na energia de soldagem que pudesse ter causado a dispersão encontrada na junta 1 seria avaliar o volume da solda depositada e o tamanho da ZAC, porém nenhuma análise microestrutural foi realizada no presente trabalho, pois o objetivo principal era analisar de 
maneira macro se as variáveis escolhidas influenciariam nas distorções angulares.

Tabela 12 - Anova: Fator Duplo com Repetição. Saída de dados para a análise de variância global dos resultados das amplitudes das distorções das PTs nas juntas 1 e 2 .

\begin{tabular}{|c|c|c|c|c|c|c|}
\hline \multirow[b]{2}{*}{ RESUMO } & \multicolumn{2}{|r|}{ Junta 1 } & \multicolumn{3}{|c|}{ Junta 2} & \\
\hline & PTा & PTL & PTI & PTI & Total & \\
\hline \multicolumn{6}{|l|}{ Sem tecimento } & \\
\hline Contagem & 6 & 6 & 6 & 6 & 24 & \\
\hline Soma & 40,4870 & 30,4220 & 67,0420 & 57,8950 & 195,8460 & \\
\hline Media & 6,7478 & $\$, 0703$ & 11,1737 & 9,6492 & 8.1603 & \\
\hline Variăncia & 9,0152 & 2,3458 & 12,8998 & 12,0816 & 13,8588 & \\
\hline \multicolumn{6}{|l|}{ Teainento Zig-Zog" } & \\
\hline Contagem & 6 & 6 & 6 & 6 & 24 & \\
\hline Soma & 47,4400 & 29,8000 & 62,9510 & 67,2680 & 207,4590 & \\
\hline Médas & 7,9057 & 4,9667 & 10,4918 & 11,2113 & 8,6441 & \\
\hline Varißneia & 8,3755 & 6,2755 & 21,0334 & 23,3946 & 19,1230 & \\
\hline \multicolumn{6}{|l|}{ Tecimento Wai-Vem" } & \\
\hline Contagem & 6 & 6 & 6 & 6 & 24 & \\
\hline Soma & 41,1100 & 37,6800 & 64,2810 & 65,4010 & 208,4720 & \\
\hline Média & 6,8517 & 6,2800 & 10,7235 & 10,9002 & 8,6863 & \\
\hline Variäncia & 3,5232 & 3,6198 & 18,8392 & 16,0993 & 13,8874 & \\
\hline \multicolumn{7}{|l|}{ Totel } \\
\hline Contagem & 18 & 18 & 18 & 18 & & \\
\hline Soma & 129,0370 & 97,9020 & 194,2740 & 190,5640 & & \\
\hline Media & 7,1657 & 5,4390 & $10, \pi 330$ & 10,5869 & & \\
\hline Variäncia & 6,4413 & 3,9767 & 15,6067 & 15,6519 & & \\
\hline Desvio Padrăo. & 2,5380 & 1,9942 & 3,9505 & 3,9562 & & \\
\hline \multicolumn{7}{|l|}{ ANOVA } \\
\hline Fonte da varioģào & sa & gl & $M Q$ & $f$ & volor-P & Faritice \\
\hline Teamento: & 4,1014 & 2 & 2,0507 & 0,1790 & 0,8366 & 3,1504 \\
\hline $\mathrm{PTY} / \mathrm{PTL}$. & 373,5889 & 3 & 124,5296 & 10.8678 & 0,0000 & 2,7581 \\
\hline interaçôes & 16,8857 & 6 & 2,8143 & 0,2455 & 0,9592 & 2,2541 \\
\hline Dentro & 687,5150 & 60 & 11,4586 & & & \\
\hline Total & 1082,0910 & $\pi$ & & & & \\
\hline
\end{tabular}

Na Tabela 12 ficou evidente também que as médias das amplitudes das distorções das PTs da junta 2 foram maiores que da junta 1 , sendo que o tipo de junta é uma variável de influência estatística nas amplitudes das distorções angulares transversais e longitudinais. Como se utilizou a mesma energia de soldagem para todos os casos, isso se deve ao fato da zona fundida $(\mathrm{ZF})$ ter sido menor nas placas de teste da junta com chanfro em $60^{\circ}$, onde a maior parte da solda se depositou acima da linha média das placas de teste devido à própria geometria da junta chanfrada, enquanto que as placas de teste da junta sem chanfro apresentaram uma ZF maior gerada pela distribuição mais homogênea da solda em toda a espessura devido à própria geometria da junta sem chanfro. Nas Figuras 9 e 10 é possível verificar o descrito.

\section{Conclusões}

- Dentro das condições testadas no presente trabalho, foi possível concluir:
- O tecimento não foi uma variável de influência estatisticamente significativa nas distorções angulares. Isso mostra que em situações de soldagem automáticas, ou mesmo semiautomáticas, as variações na técnica de tecimento utilizadas pelo programador de robô ou soldador, normalmente utilizadas no chão de fábrica, não implicam em problemas de qualidade dimensionais na montagem dos conjuntos finais.

- O sentido de laminação da chapa em relação ao cordão de solda não foi uma variável de influência estatisticamente significativa nas distorções angulares, levando-se em consideração a dispersão de dados gerada pelas diferentes formas de distorções encontradas na junta sem chanfro e a não realização de análises microestruturais.

- A área transversal de metal fundido acima ou abaixo da linha média das placas de teste (no sentido da espessura) foi o fator determinante para as formas de distorções angulares transversais e longitudinais, ou seja, pela formação do perfil parabólico para cima e para baixo.

- A junta chanfrada em $60^{\circ}$ apresentou maiores amplitudes de distorções angulares se comparada à junta sem chanfro, principalmente pela diferença entre ambas quanto à zona fundida e a quantidade de solda em relação à linha média da placa de teste (no sentido da espessura), ou seja, o tipo de junta é uma variável de influência estatisticamente significativa nas amplitudes de distorções angulares.

- A junta sem chanfro apresentou variação dimensional rotacional (distorção rotacional) mostrando que esse tipo de junta é propício a esse problema, se não adotadas as medidas corretas no processo.

- A aplicação prática do processo de soldagem GMAW-P robotizado em liga de alumínio na indústria metal-mecânica é viável tecnicamente, tendo boa versatilidade.

\section{Agradecimentos}

A Faculdade de Engenharia Mecânica da UNESP campus Bauru e a empresa Máquinas Agrícolas Jacto S.A pela infraestrutura disponibilizada, e aos professores Yukio Kobayashi e Gilberto de Magalhães Bento Gonçalves pelas sugestões e contribuições durante a realização do trabalho.

\section{Referências Bibliográficas}

[1] TOROS, S.; OZTURK, F.; KACAR, I. Review of Warm Forming of Aluminum-Magnesium Alloys. Journal of Materials Processing Technology, p. 1-12, 2008.

[2] ALCAN. Manual de Soldagem. Alcan Alumínio do Brasil S/A, 1. ed., 1993.

[3] BILONI, H.; PÉREZ, T. E.; SAGGESE, M. E.; SOLARI, M. J. A. Manual de Soldadura de Aluminio. Proyecto Especial de Aluminio OEA - CNEA, Gerencia de Investigacion y Desarrollo, Aluar Aluminio Argentino. Buenos Aires, 1981.

[4] TREMONTI, M. A. Incorporar a Robótica Aplicada à Soldagem: As Questões Organizacionais para se Obter Sucesso. Departamento de Soldagem da Fatec. São Paulo, 2000.

[5] VIEIRA, L. A.; BRACARENSE, A. Q. Soldagem Robotizada GMAW de Alumínio. In: XXX Consolda Congresso Nacional 
de Soldagem, Rio de Janeiro, Setembro 2004.

[6] KIM, Y. S.; RHEE, S. A Study of Heat Input Distribution on the Surface During Torch Weaving in Gas Metal Arc Welding. JSM International Journal, v. 48, p. 144-150, 2005.

[7] FRATARI, R. Q.; SCHVARTZMAN, M. M. A. M.; SCOTTI, A. Otimização dos Parâmetros de Tecimento para Confecção de Amanteigamento em Chapas de Aço ao Carbono Pelo Processo TIG com Arame AWS ER309L. Soldagem e Inspeção, São Paulo, v. 15, Jul/Set 2010.

[8] KAISER ALUMINIUM \& SALES. Welding Kaiser Aluminium. California, 1978.

[9] MARQUES, P. V.; MODENESI, P. J.; BRACARENSE, A. Q. Soldagem Fundamentos e Tecnologia. Belo Horizonte: Editora UFMG, 2005. 362 p.

[10] FRAGA, F. E. N. Proposta de Modelo para Caracterizar Susceptibilidade a Distorção Devido à Soldagem em Chapas de Alumínio: 2009. 138 p. Tese (Doutorado em Engenharia Mecânica), Unicamp, Campinas.

[11] MAZZAFERRO, J. A. E.; MACHADO, I. G. Método Computacional para Previsão de Distorções em Chapas de Alumínio Soldadas a Topo pelo Processo MIG. Soldagem \& Materiais, São Paulo, p. 36-41, 1992.

[12] RADAJ, D. Welding Residual Stresses and Distortion: Calculation and Measurement. Düsseldorf: Ed. DVS-Verlag, 2003. $397 \mathrm{p}$.

[13] AWS. Welding Handbook, Welding Science \& Technology. American Welding Society, v. 1, 9. ed., 2001.

[14] AWS. Structural Welding Code - Aluminum. ANSI/AWS D1.2/D1.2M:2003. American Welding Society, 4. ed., Miami, USA, 2003.

[15] ASTM. Standard Specification for Aluminum and Aluminum-Alloy Sheet and Plate. ASTM B209M - 04. American Society for Testing and Materials, 2004.

[16] RESENDE, A. A. Uma Contribuição a Análise dos Parâmetros de Soldagem do Processo Plasma-MIG com Eletrodos Concêntricos: 2009. Dissertação (Mestrado em Engenharia Mecânica), UFU, Uberlândia.

[17] LEVINE, D. M.; BERENSON, M. L.; STEPHAN, D. Estatística: Teoria e Aplicações. Usando Microsoft Excel em Português. Rio de Janeiro: LTC, 2000. 811 p.

[18] COSTA NETO, P. L. O. Estatística. 2. ed, São Paulo: Edgard Blücher, 2002. 